\title{
DIRECTIONS TO IMPROVE APPLICATION OF SYSTEMS APPROACH TO FIRE PROTECTION REQUIREMENTS FOR BUILDINGS
}

\author{
Harold E. Nelson \\ Chief, Program for Design Concepts, Center for Fire Research, National Bureau of Standards, \\ Washington, D.C. 20234
}

(Received 25 May 1977)

\section{ABSTRACT}

Recent and progressing work in the development of systems approach for design of fire protection in buildings is examined. Scope of coverage includes such areas as review of fire safety systems approach in the U.S. and an overview of extensive and more pertinent fire growth systems analysis approaches. A fire model with its impact based on a state's-transition concept is proposed. Fire is viewed as two distinct sequences: fire behavior and human behavior. Finally, a plan for the derivation of viable firc protection engineering technology is presented.

Keywords: Critical events, decision trees, fire behavior, fire growth, fire safety, rate constants, state's-transition, systems approach, models, probability.

RECENT IHISTORY OF THE DEVELOPMENT OF SYSTEMS APPBOACH TO FIRE SAFETY IN THE UNITED STATES

It is worthwhile to view briefly the history of systems development in fire safety in the United States. Of particular interest is that portion of the history that relates to the use of event trees as a principal instrument in total building fire safety performance analysis. The "success" or decision type of event tree is a candidate alternative to the current approaches used in building codes.

The event tree methodology has its technical antcoedents in reliability analysis and fault tree analysis. Both of these approaches have been extensively examined in the United States. An excellent review of the state-of-the-art at varying levels of sophistication in reliability and fault tree analysis is contained in the recent publication, Reliability and Fault Tree Analysis

${ }^{1}$ Presented at the Society of Wood Science and Technology Symposium, Trends in Fire Protection, Session II-Technology and Research, Madison, WI, 20 April 1977; and to be published in the Proceedings of the UJNR Panel (United States and Japan Panel on Natural Resources) held 21 October 1976 in Tokyo, Japan, at the Building Rescarch Institute. by the Society for Industrial and Applied Mathematics (1975).

The recent history of milestones in the application of such systems' concepts to the determination of fire protection requirements for buildings can be chronicled approximately as follows:

A. International Conference on Fire Safety in High-Rise Buildings-Airlie, Virginia, 12-16 April 1971. The report of this conference (Gen. Serv. Admin. 1971) strongly emphasized the need for a total systems design and management approach in transferring new design and use concepts to the creation and operation of modern high-rise buildings. The conference report made a number of proposals listing the general elements for such a system.

B. Seattle Federal Building. The Seattle Federal Building was chosen by the General Services Administration (GSA) to be used as an example of potentials for engineered fire safety for high-rise buildings. The author, then Director of Accident and Fire Prevention for the General Services Administration, reviewed the proposed design of the Seattle Building in consultation with the de- 


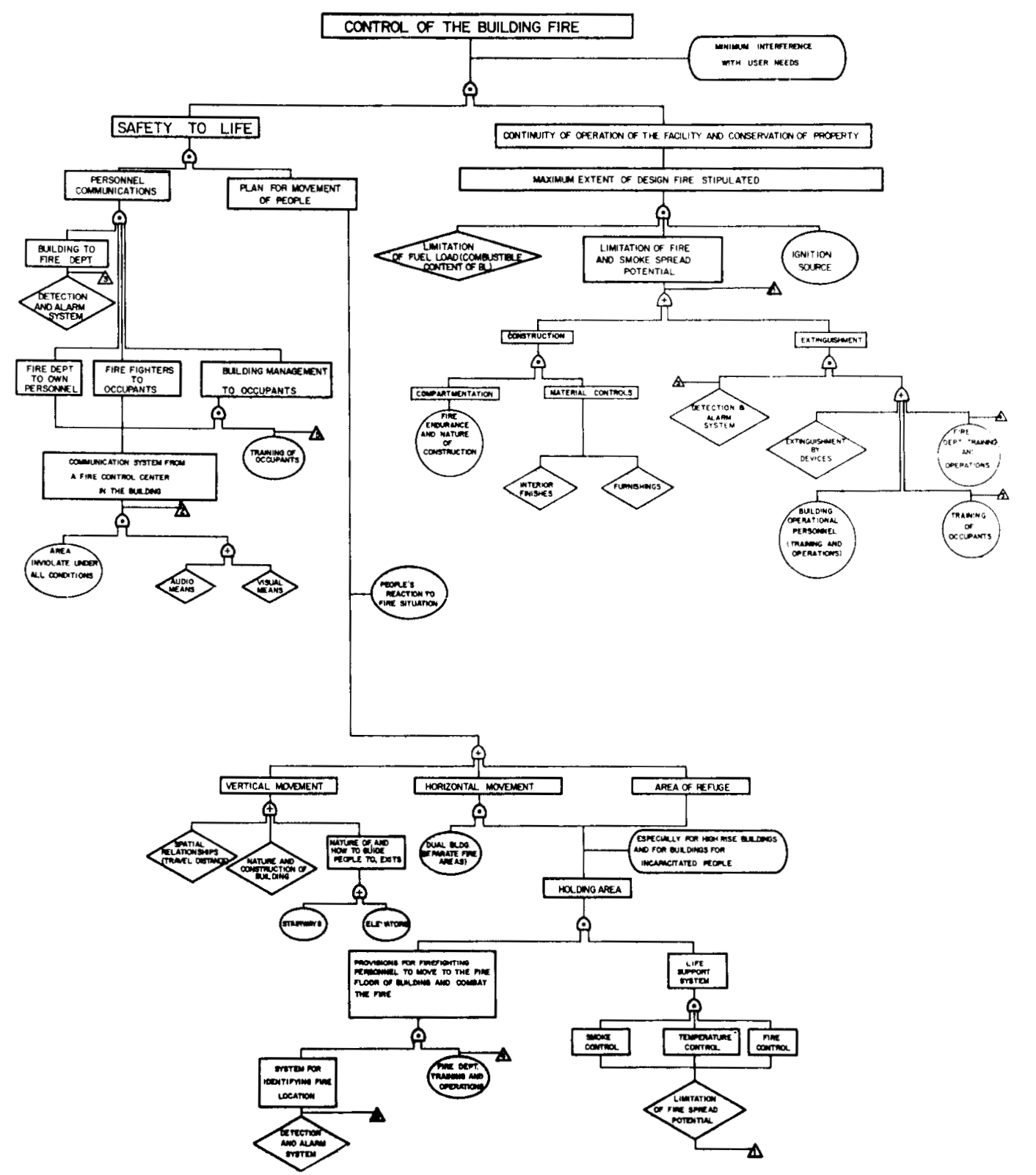

Fro. 1. NBS fault tree-control of the building fire.

sign team and unilaterally selected the fire safety requirements for that building. This occurred in June 1971. While the items selected were the best judgment of the writer in terms of systematic approaches to fire safety, there was no systems technique developed at that time. The Seattle Federal Building can best be considered as the father rather than the child of systems approach techniques.

C. Reconvened International Conference on Fire Safety in High-Rise Buildings, Washington, D.C., October 5, 1971. 


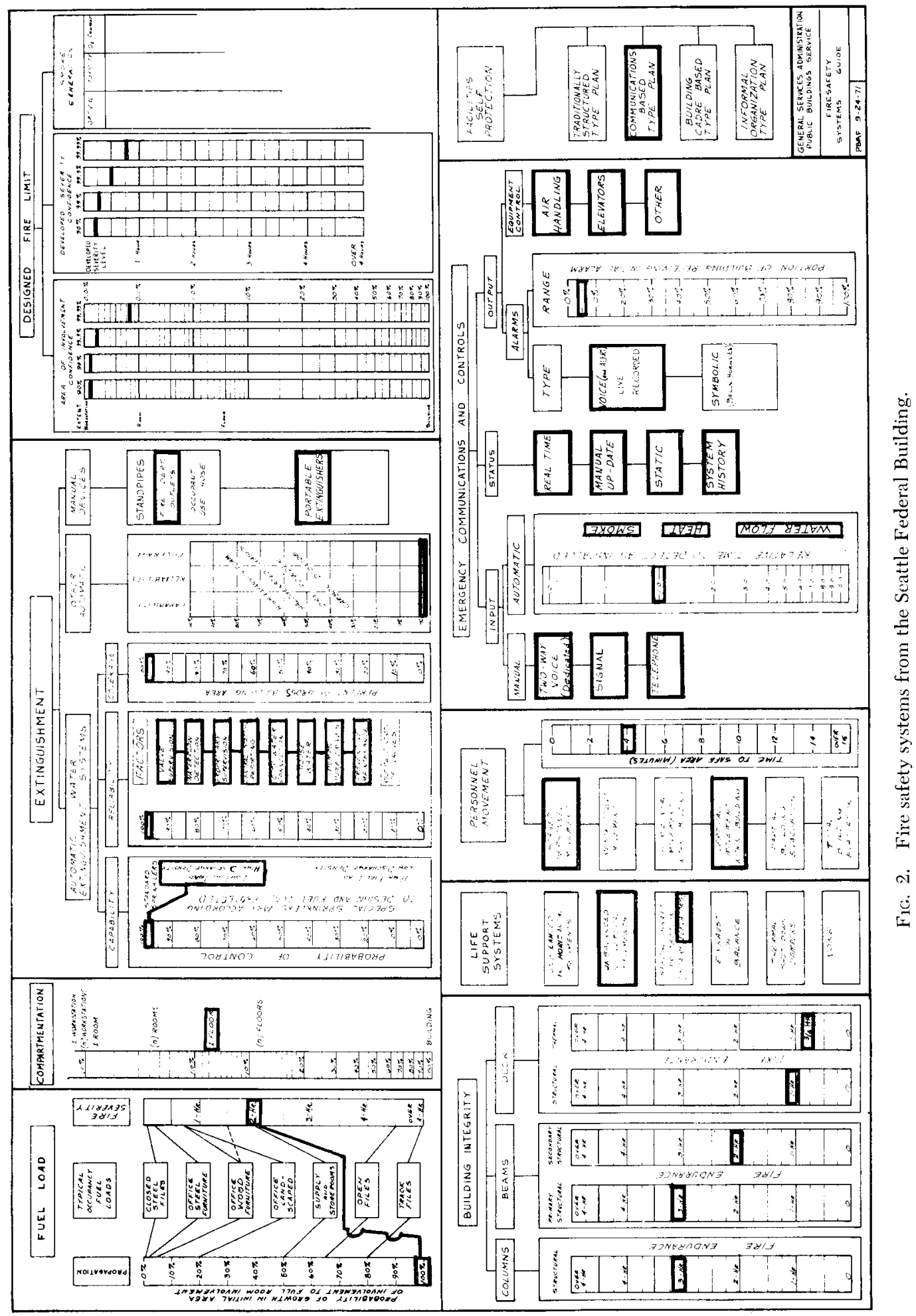




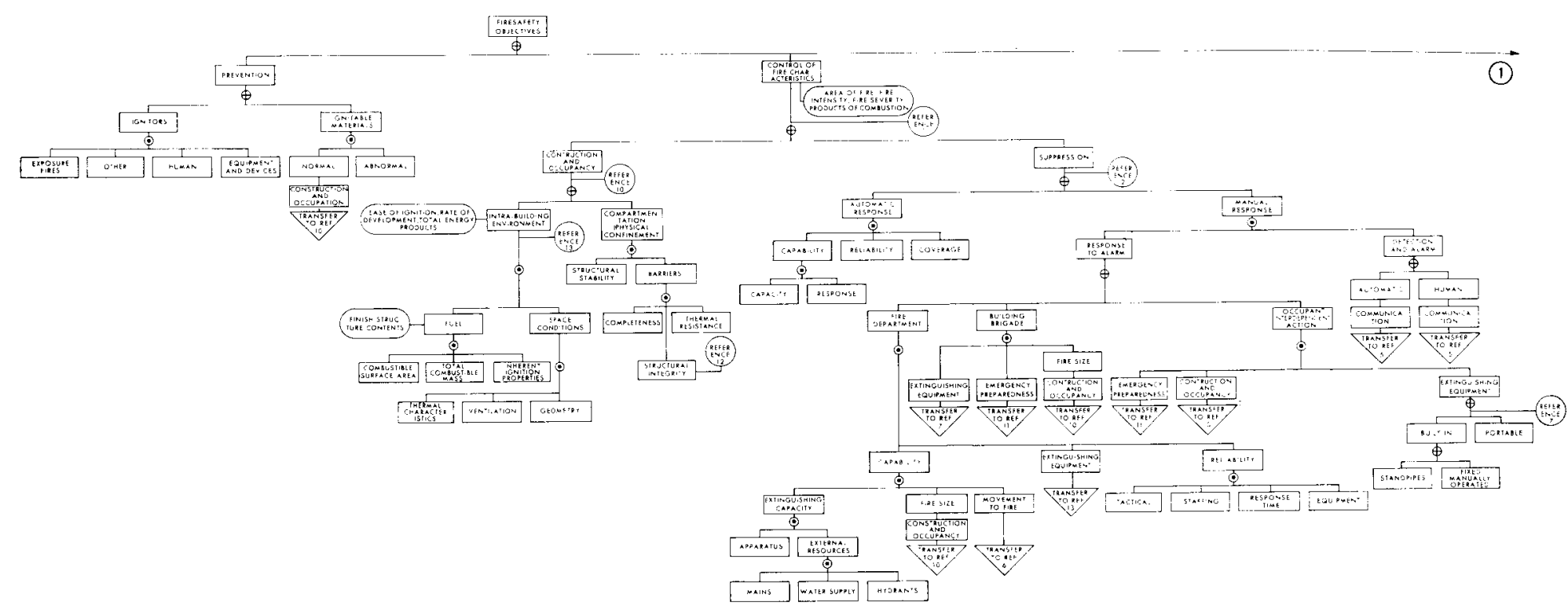

FIs. 3. National Bureau of Standards-General Services Administration Decision Tree. 


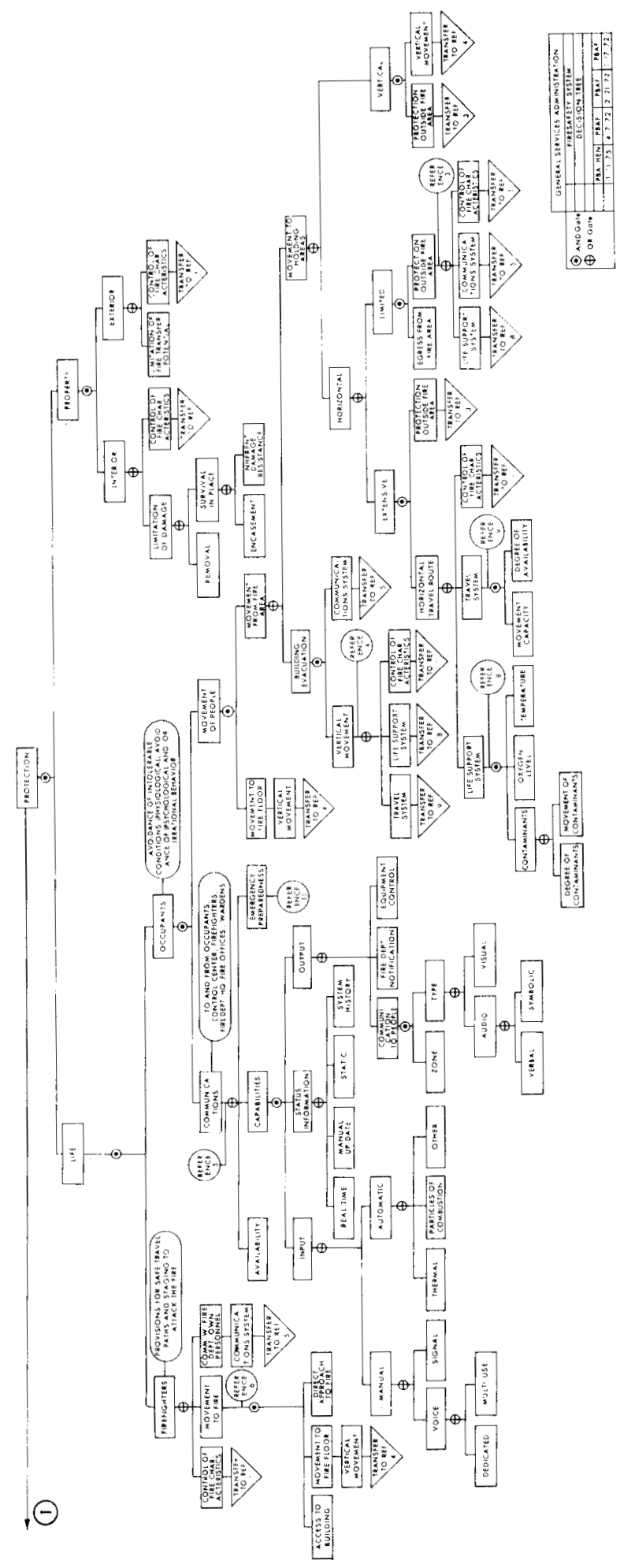


This conference was important primarily in two aspects:

1. A presentation entitled "A Method of Analysis for Control of Building Fire" was delivered by Mr. Irwin A. Benjamin, National Bureau of Standards. Included in this presentation was a fault tree cvent logic diagram considering the elements or events essential to the control of the building fire. This fault tree is reproduced as Fig. 1.

2. The author presented a review of the firc safety systems for the Seattle Federal Building. Fire protection elements were summarized in a fire safety systems guide sheet (Fig. 2). Figures 1 and 2 constitute the first attempts to make logical analysis of the total fire safety systems in buildings.

D. GSA Decision Tree. A joint effort by NBS and GSA (General Services Administration) developed a success tree aimed at determining the various approaches available to achieving fire safety objectives in buildings. This was then taken by GSA through several revisions and generations. The current version is shown in Fig. 3. This is the basic reference document in the GSA goal-oriented systems approach.

L. National Fire Protection Association (NFPA) Systems Committee. In 1972 the NFPA formed the Committee on Systems Concepts for Fire Protection in Structures. This Committee, using the background for all the preceding items, developed a success tree. The current version of that success tree is available from NFPA. The principal difference between the GSA and the NFPA tree is in mamner of expression. The GSA tree generally uses a quasi-algebraic approach that attempts to express the subdivision of each event as functional elements of that event. The NFPA tree expresses itself in terms of cause and effect. At each gate in the NFPA tree, an attempt has been made to ensure that the events below the gate represent all causal elements of the event above the gate.

F. GSA Systems Approach. The General Services Administration produced the "Interim Guide to Goal Oriented Systems Approach to Building Fire Safety" (1972). This was published as GSA internal criteria and currently is the only completely described analytical system for probabilistic evaluation of the expected success in total performance of fire safety in biuldings.

G. Application of the GSA Goal-Oriented System to Building Design. GSA has applied the goal-oriented systems approach to several buildings and has used the results to acquire the data base of information as essential elements in making design determinations. The level of confidence in the system at this time, however, is such that the systems output can be considered an important input but not a sole determiner of major design decisions. Where the systems approach indicates a solution in conflict with traditional (i.e. code type) approaches, it is important that the conflict be resolved on its technical merits rather than any assumption of corrections inherent in either approach. The largest single structure and most extensive application of this has been to the Atlanta Federal Building. This building has currently been designed though not yet built. In 1974 GSA published a report of the application of the goaloriented system to the Richard B. Russell Court House and Federal Building now under construction in Atlanta, Georgia.

H. NFPA/Department of Housing and Urban Development (HUD) Study. In 1975 HUD awarded a contract to the National Fire Protection Association to undertake a study of the application of systems analysis and the success tree approach to residential types of structures. This project is now underway. The most significant potential of this project to date is work done by its subcontrac- 
tor, Mr. Ed Comelly, OMNEMII Incorporated, in the modeling support for the study.

I. Recent Development in Systems Dynamics/State's Transition. The interplay of the participants in all of the above activities has resulted in new concepts. These generally relate to the conditions that govern or dominate any statc of fire development, the transition from state to state and the interplay between the states and transition, and the actions of humans or the impact of fire protection measures. These are discussed in more detail later under the hoading Directions.

SYSTEMS TO DESCRIBE FIRE GROWTHPIYYICAL MODELS/COMPUTER MODELS

Most of the inputs currently used by those working with the systems approach are the same as those used in code application and fire insurance considerations. These consist primarily of experience, data from individual tests, separate research results, personal experience, and collected concensus opinion. This imposes important constraints on the use of current systems approach techniques because of the limited degree of confidence that can be placed on inputs into the system related to fire growth factors. Several different deterministic types of fire growth concepts and fire growths models, however, are currently being developed. One or more of these may make a major contribution towards raising the confidence levol in total systems approaches to the point where it would be reasonable to use systems analysis as the unilateral determinant of fire safoty requirements.

A conceptual approach to evaluative fire growth has been published under the title "Systems Analysis of Energy Environment in Buildings" (Nelson 1972). This study conceived fire in a step-by-step growth process. Its principal value at this time is in evaluating the various states and transitions involved in fire growth.

Efforts have also been directed towards development of empirical models to describe fire growth in more quantitative terms. All of the major efforts in this area involve incremental finite analysis as the basis of the cmpirical approach. Each of the three major contributions in this area has, however, approached the problem of modeling a fire from a different perspective.

(1) Dr. John A. Rockett in 1969 proposed a model based on subdividing the entire volume of the building or space into cubicle elements and undertaking an analysis of interactions between and within the cubes. In an article discussing the proposed model, Rockett expressed the significant problem as the volume of data necessary to be handled. He expressed confidence in the ability of such a system to handle gross action. However, he expected that fine details about the course of a fire or the movement of smoke would not be susceptible to such analysis for some time. Rockett is not personally continuing to work in this area, but others are using the programs he developed and other aspects of his initial studics.

(2) A University of Dayton Research Institute (UDRI) team with Mr. Jerry Reeves as principal investigator has developed a computerized program for description of fire development (unpublished). In the UDRI approach the positions of all elements in a space are described and the finite fire growth analysis is described as incremental spaces on the surfaces of the combustible materials. This program was designed to predict fire development in aircraft interiors and is predicated on spread along contiguous surfaces and transfer across spaces separating such surfaces. The program input is taken from rate of heat release of the exposed materials with the test values measuring speed of flame propagation horizontally, upward, and downward at varying lcvels of incident flux. To date, the model has not been proof-tested and has not yet been released for public view. Full-scale tests of the system are to be made in the near future, using aircraft cabin burn-out tests. 
(3) Tom Waterman and Ronald Pape at the Illinois Institute of Technology Research Institute, working on a grant from the Center for Fire Research at NBS, have proposed a system which they refer to as semistochastic. In their approach, the space is described in terms of its constituents with all fucls identified as boxes located in this space. The input required is basically the rate of heat release of the individual boxes as would occur in a free-burning test situation. Using empirical energy input data from numerous tests of furniture and fuel loads in rooms and spaces, they have developed a computerized system. The system interfaces these data with the impact of the enclosing space, the separation of fuels, and other factors to determine the time, intensity, and form of fire spread, chergy development, and combustion product development in the room of fire origin. This program has been completed and is now being reviewed by members of the staff of the Center for Fire Research. Fullscale testing will be conducted at NBS and results will be correlated with the model.

\section{SYSTEMS FOI THE ANALYSIS OF BUILDING FIRE SAFETY DESIGN}

Current approaches to systems analysis for determining building fire safety requirements are based primarily on the decision-tree approach presented by GSA (1972).

In this approach, the term "event" is used to describe any physical condition, use factor, activity, or action that can cause or control fire, its effects, or the response to fire. The use of a decision tree approach of this type provides the user with a unique capability to:

1. Study and determine the organization of the various "events" that control or determine fire and the response to fire;

2. Establish the interrelationships between these events, and the sequence in which the impact of events must be considered; and
3. State the level of success or other measurements of performance in a given situation.

All systems approaches (1) are limited by the validity of the data used and (2) require understanding of the meaning of the statements of success or performance produced.

With these capabilities and limitations in mind, the objective of the systems approach is to achieve a better and more exact understanding of the degree of safety provided, along with the ability to determine the impact of individual events or the sensitivity of the system to change during that event. In addition the systems approach will give:

1. A mechanism to allow design innovations and options that best combine the necessary degree of safety with all of the other building design features.

2. A basis to evaluate cost effectiveness, where safety worth can be related to cost not simply in terms of monetary differences but in relation to actual safety impact per dollar invested.

3. A system whereby the responsible authorities, be they code officials, underwriters, owners, or others can evaluate whether safety goals are being met, without having to review each specific design requirement or variation.

The tree network is a diagrammatic means of showing a complete event/logic system that progressively subdivides the problem into smaller and smaller elements to the level at which the user wishes to make input into the system. The tree arrangement assists in pointing out events that must occur simultaneously or independently; showing which events can contribute most effectively to reaching a goal; and expressing the choices or trade-offs to insure a satisfactory goal or objective level. The tree does not within itself show the extent of conditionality or exclusivity. It does, however, provide a visual arrangement that can assist the user in identifying where 
questions regarding exclusivity or conditionality must be resolved.

In a decision tree, the levels of events are connected by gates. There are two types of gates: the "and" gate and the "or" gate. The type of gate used indicates the relationship of the events below the gate to the success of the events above the gate in the decision tree.

The location of an "and" gate between two levels of events signifies that all of the events in the level immediately below the gate are necessary for achievement of the success of the event above the gate. Exclusion of any element directly connected to the lower side of an "and" gate precludes success of the event above the gate. Therefore, the maximum probability of success of an event above the "and" gate is limited to the lowest probability of success of any event commected to it. The probability of success for achieving the goal objective of an event above an "and" gate is shown pictorially in the upper part of Fig. 4.

In the success type of decision tree, an "and" gate probability of success in achieving the goal objective of element $A$ is:

$$
P_{A}=\left(P_{B_{1}}\right)\left(P_{B_{1}}\right) \ldots\left(P_{B_{x}}\right),
$$

where the events at the $B$ level are independent, or:

$$
P_{1}=\left(P_{B_{1}}\right)\left(P_{B_{2}} / P_{B_{1}}\right) \ldots\left(P_{B_{N} /} / P_{B_{1}} \& P_{B_{2}}\right),
$$

where the events at the $B$ level are interdependent, where

$$
\begin{aligned}
P= & \text { Probability of success of subscripted } \\
& \text { element } \\
/= & \text { Probability conditional on preceding } \\
& \text { element }(\mathrm{s}) \text {. . . read as "given." }
\end{aligned}
$$

An example of an "and" gate extracted from the GSA tree is shown on the lower left of Fig. 4. Here the success of a barrier is dependent on the barrier's being complete. It is also equally dependent on maintaining its structural integrity if exposed to fire. And finally, it is dependent upon thermal resistance in preventing the passage of ignition temperatures to the unexposed side of the wall.

On the lower right of Fig. 4, an "and"
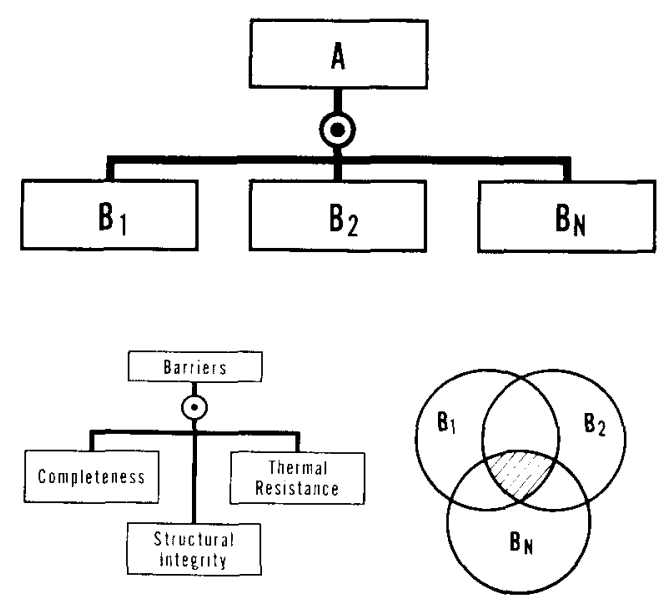

FIs: 4. "And" gate.

gate is depicted in the form of a Venn diagram. The degree of success is equal to the degree of intersection of all of the elements.

Figure 5 provides graphic examples for determining the probability of success in achieving a goal objective through an "or" gate. In the success type of decision tree, the "or" gate probability of success in achieving the goal objective of element $A$ is:

$$
P_{A}=\left(P_{B_{1}}\right)+\left(P_{B_{2}}\right) \ldots+\left(P_{B_{N}}\right)
$$

where the events at the $B$ level are mutually exclusive, or:

$$
\begin{aligned}
& P_{1}=1.00-\left[\left(1-P_{B_{1}}\right)\left(1-P_{B_{2}}\right) \ldots\right. \\
& \left.\left(1-P_{k_{x}}\right)\right] \text {, }
\end{aligned}
$$

where the events are not mutually exclusive but are independent, or:

$$
\begin{gathered}
P_{A}=1.00-\mid\left(1-P_{B_{1}}\right)\left(1-P_{\left.B_{2} / P_{B_{1}}\right) \cdots}\right. \\
\left.\left(1-P_{B_{\mathrm{W}}} / P_{B_{1}} \& P_{B_{2}}\right)\right]
\end{gathered}
$$

where the events are not mutually exclusive and are interdependent.

An "or" gate is a point of potential design trade-off. An example of an "or" gate from the GSA tree is shown on the lower left of Fig. 5. This indicates the supportive interplay between suppression systems, the built-in construction features, and the fire potential of the occupancy.

On the lower right of Fig. 5, the "or" gate 

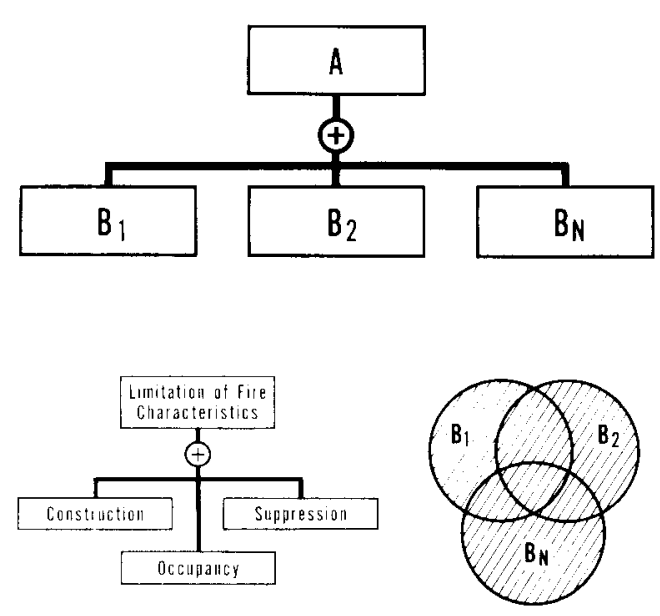

FI(s. 5. "Or" gate.

is depicted in the form of a Venn diagram. The degree of success is equal to the union of success provided by any individual element or combination of clements.

The location of an "or" gate between two levels of events signifies an "and-or" relationship. In this case, total inclusion of all of the events below the gate is desirable, but not necessary, to achieve the goal of the event above it. Exclusion of any event connected to the lower side of an "or" gate does not preclude success of the event above that gate. The probability of success of an event above an "or" gate is always equal to or greater than the highest probability of success of any of the events connected to it. Figure 5 provides graphic examples and formulae for determining the probability of success of achieving a goal objective through an "or" gate.

Both the GSA and the NFPA decision trees are amenable to the probabilistic approach upon which the GSA goal-oriented system is based. These decision trees have been extensively examined by groups interested in fire safety and are felt to represent sound representations of the elements that determine the course of fire development and growth and its impact on people and property. Other trees could be developed that would be as effective. The actual events in the tree are not individually important. It is necessary, however, that any alternative tree seeking to produce the same results follow the protocol of starting from the same top event "Fire Safety Objective" and at each step divide the entire universe of events as either an "and" or an "or" function. At each gate the subordinate events must sum to be the total universe of events that constituently add up to the event above the gate. If this is not followed at an "and" gate, the result will be failure to protect against a potential systems failure. If an element is omitted at an "or" gate, the result will not reduce the potential safety but would reduce the flexibility of choice in the system by eliminating one or more alternatives.

\section{DIRECTIONS}

The goal-oriented systems approaches have been valuable in giving indications of the extent of the impact of fire. They are currently limited in their ability to include rate or time factors and in the lack of an adequate store of fire protection engineering data. This lack of data forces the system to use either engineering opinion or consensus committee type of decision for many of the most important inputs. To overcome these limitations, it is necessary to find better linkages between applied fire protection and scientific and/or empirical engineering data and to develop a procedure that relates to fire growth. In addition, a better methodology is needed for interrelating human action as it impacts either on the fire and its development or on the safety of persons exposed to fire.

Recently, a combined concept has emerged. This resulted from examinations of the various concepts on energy development, the systems approach, and data being developed by current research. In this concept, both the fire growth modeling systems and building fire safety design systems approaches described above are combined into an integrated system. The purpose of this new approach is to provide a more complete base of knowledge by which rational inputs can be made into a decision tree analysis. 
This concept is based on the premises that:

1. Fire behavior and the behavior of persons involved can be expressed as series of realms connected together to form sequences.

2. The fire behavior and people behavior sequences are separate, but can be (and often are) interacting with each other. (A typical interaction is the opening or closing of the door to a room that is on fire.)

3. A sequence consists of individual periods of consistent behavior pattern, varying in length, and beginning and ending with a critical event. These periods of consistent behavior are called "realm" when discussing fire behavior and "episodes" when discussing human behavior. (The burning of a chair might be a typical realm; if a second item becomes inrolved or the room flashes over, the rate of burning will significantly change and a new realm will exist.)

4. For each realm there is a "rate constant" which, if identificd, can describe the rate of change during that realm. A change in the rate constant constitutes a change in realm. (The chair described above burns, releases energy, or produces smoke at a consistent acceleration; if the reatm changes, this rate of acceleration (hanges.)

5. At any instant in the combined fire behavior/human behavior sequences, there is one and only one value for each behavioral property. These properties are called "state's conditions" and are identifiable and potentially quantifiable (for example, the size of the flame or rate of smoke production)

6. There are potentially identifiable factors in the decision tree events that control both the rate constant within a realm and the level of events that determine the start and termination of a realm. These factors are described by both the CSA and NFPA trees; but the individual dominance or proportional impact of a single factor is not directly identifiable from the decision tree approach. In terms of the sequence, a significant change in a dominant factor, its degree of dominance, or the entry of new "dominant factors" will result in a change in the rate constant and thereby a change in realm. (A prime example of this occurs in the transition through flashover. Prior to flashover the fuel properties such as ignitability and fuel arrangement dominate the fire development and energy levels. After flashover the dominant factors are ventilation and total amount of available fuel.)

Fire Behavior Sequence. Figure 6 is a modification of the overview design presented by Gen. Serv. Admin. (1972). This figure presents the major sequences (or "phases") in fire development. The input arrowheads at the left of the figure indicate the necessity for the combination of energy in a particular environment to have a fire start.

Energy as shown means the input or potential ignition energy to start the fire sequence. Environment describes the physical situation consisting of fuel, geometry, construction, ventilation, and general layout and arrangement existing at the moment of introduction of the energy source.

The development and spread of fire and fire energy through a facility are then divided into five basic phases each of which will consist of one or more realms. The division of phases is based on the expected types of dominant factors. These are:

1. The Ignition-Initiation Phase covers the period from the entry of the potential ignition energy to the point of self-sustained burning of one or more items. In this phase, the development is almost entirely dominated by the transfer of energy from the ignition source to the target, the ruaction to this energy by the target, and the critical ignition parameters of the target material. The shape of the target and the arrangement or geometry of the environment have little to do with ignition or development realms in this phase. 


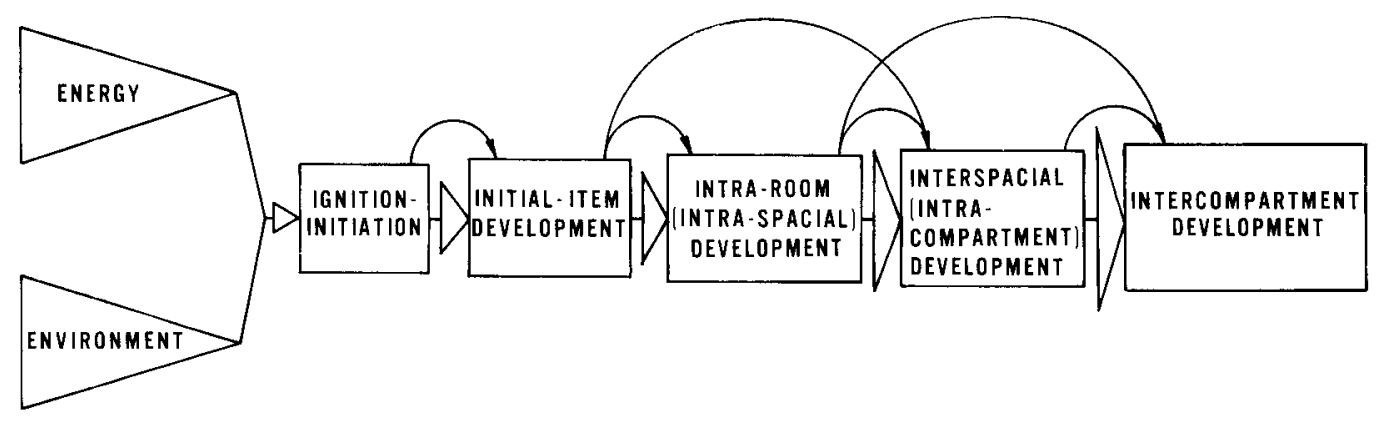

FIG. 6. Overvicw diagram of fire behavior sequence.

2. The Initial Item Development Phase is the second phase and covers the development of fire from the initiation of a self-sustained flame to the point where the fire either terminates or extends to one or more additional items. In this phase not only the basic physical properties of the material but its shape and form, the spacing and arrangement of other materials ( second targets), and the space configuration and ventilation begin to play parts.

3. The Intra-Room Development Phase concentrates on the spread of fire between items within a room or space up to the point of fire termination or flashover in a room. In this phase the additional elements of radiation from the burning item or its flame, the degree of separation between items, and other space factors come into more important pliay.

4. The Interspatial Propagation Phase covers the spread of fire from space to space through unprotected openings. In this phase, important factors related to ventilation, transfer of combustion products, convected energy, and radiated energy dominate over the basic fuel considerations more important prior to flashover.

5. The Intercompartmental Spread Phase considers factors related to spread of fire when a physical barrier exists. Here the impact of total fire severity on structural elements leading to building collapse or ignition due to conduction of energy are the most important and dominating considerations.

The arched lines in Fig. 6 going from phase to phase are a schematic representation of the fact that it is not necessary to progress totally through any phase before passing through the next phase. In fact, the development conditions necessary for a critical event may cause a jump to a next phase or even skip an entire phase.

State's Conditions-Fire Sequence. The "state's conditions" describe the state of fire behavior at any instant in the sequence. Fire development subsequent to any instant is dependent upon the state's conditions and the realm at that instant, but is not dependent on the history of how that set of conditions came to be.

The state's conditions necessary to describe the fire state at a given time are:

1. Fire Bed Location. Described in terms of the size and location of the energy generator. It includes both the basic burning area and the area away from basic burning area where gaseous combustion is taking place.

2. Energy Release. Expressed both in terms of the rate of energy release at a given instant and the total energy released in the course of the fire accumulated to that instant.

3. Pyrolysis Products. States in terms of concentrations and rate of change in concentrations. Covers the nonenergyreleasing aspects of fire products such as 


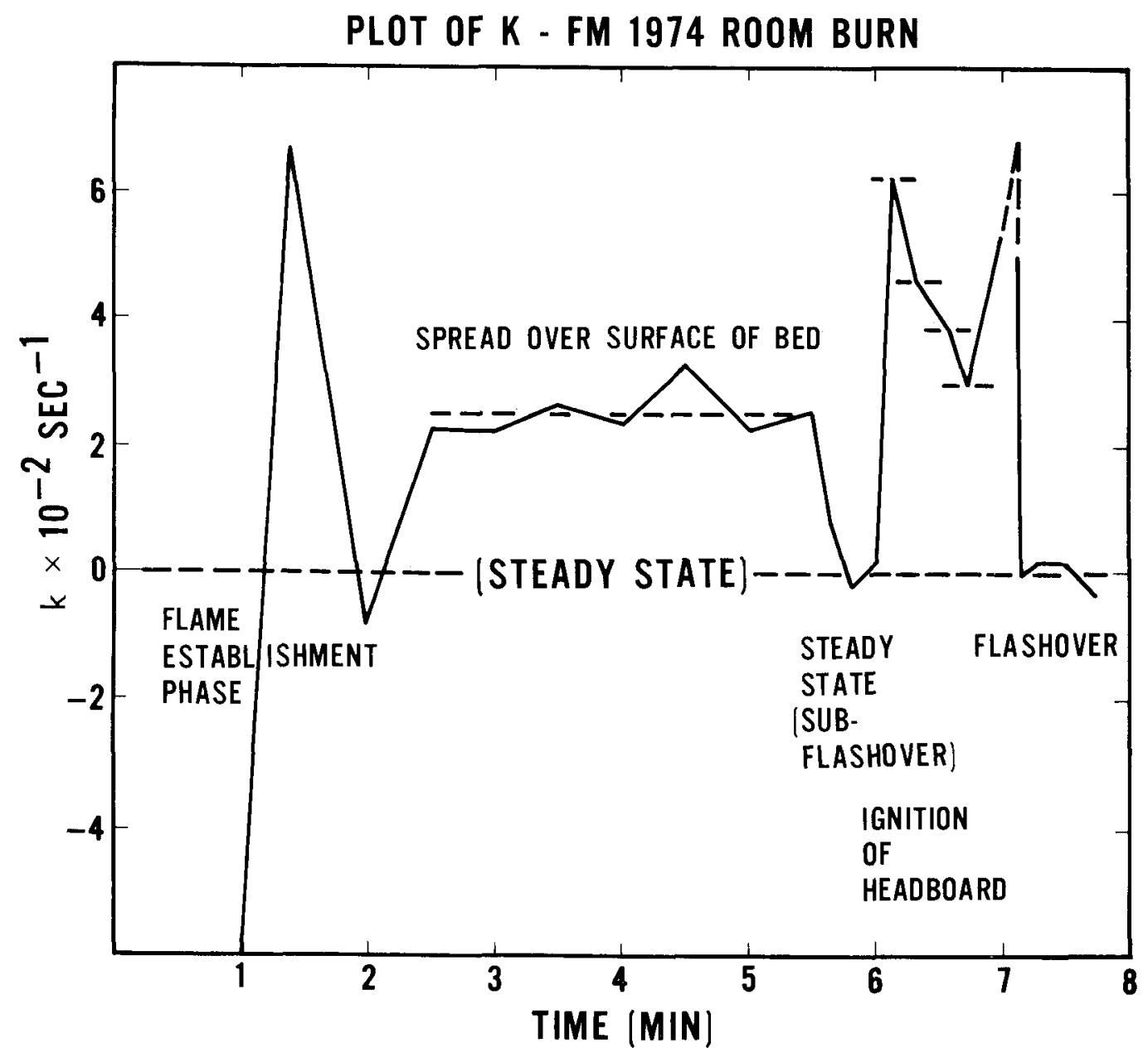

Fic. 7. $k$ values ( 1974 Harvard/Factory Mutual test).

particulates, gases, vapors, be they toxic or nontoxic, visible or nonvisible. In the case of chemical products, it also includes the rate of subsequent change in the chemical products.

Rate Constant of Realm. Various research projects and tests where rates of energy production or other reasonable measurements indicative of rates of energy or products production have been taken indicate that under fire conditions the energy release rate in a given realm varies at a constant rate of acceleration. This rate constant is determined by reaction of the total fuel and environment conditions to fire energy in- put. The formula for each realm is the same, but there is a different factor $(k)$ for each realm. The definition of a realm is the period of fire development with a constant $(k)$. In terms of a single realm, the formula for the energy release state's conditions, is believed to be:

$$
\begin{aligned}
\dot{q}_{n}= & \dot{q}_{i} e^{\text {I.t }} \\
k= & (1 / t) \ln \left(\dot{q}_{n} / \dot{q}_{i}\right) \\
\dot{q}= & \text { rate of energy release } \\
\dot{q}_{n}= & \dot{q} \text { at any instant within a realm } \\
\dot{q}_{i}= & \dot{q} \text { at another prior instant within } \\
& \text { the same realm }
\end{aligned}
$$




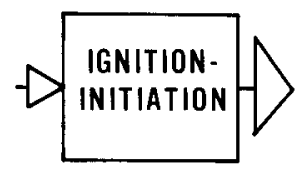

REALMS

- PREHEAT

- GLOWING COMBUSTION

- SUPPORT FLAMING COMBUSTION
DOMINANT FACTORS

- ENERGY INPUT

-INCIDENT ENERGY

-FLAME CONTACT

- fuel Response -THERMAL INERTIA - IGNITION TEMPERATURE -FUEL GEOMETRY
CRITICAL EVENTS

- IGNITION

- FLAME

- TERMINATION OF IGNITION SOURCE

- STEADY FLAME

FIG. 8. Ignition-initiation phase.

$t=$ time between $i$ and $n$

$k=$ rate constant for the realm.

As one test of this concept, data from the 1974 full room burn conducted as part of the Harvard/Factory Mutual home fire tests were calculated using this formula. Figure 7 is a plot of the values of $k$. This plot shows a marked consistency between the value of $k$ and the observed realms in the fire. The plot is superimposed with labels of the observable realms.

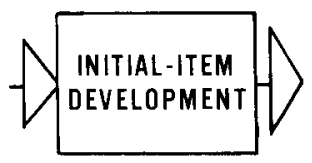

REALMS

- SPREADING ON A SURFACE

- MULTI-SURFACES

- steady State

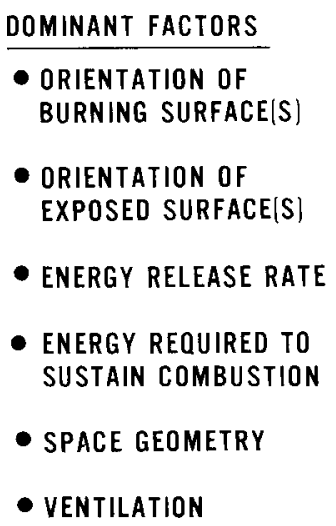

- ORIENTATION OF

- energy release rate

- energy required to

- sPaCE geometry

- VENTILATION
CRITICAL EVENTS

- steady flame

- IgNITION OF NEW SURFACE

- IGNITION OF NEW FUEL.

- eXTENSION OF BURNING THE FUEL PERIMETER

- INVOLVEMENT OF SECOND ITEM

FIG, 9. Initial-item development phase. 


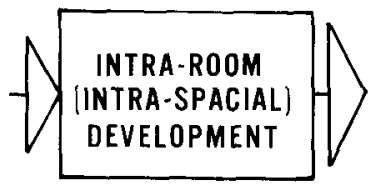

REALMS

- INVOLVEMENT OF SECOND ITEM

- INVOLVEMENT OF ADOITIONAL ITEM(S)

- FULL ROOM INVOLVEMENT

- STEADY-STATE
DOMINANT FACTORS

- ITEM BURNING RATE

- enERgy RELEASE RATE

- ITEM SPACING

- ITEM IGNITION SUSCEPTIBILITY

- SMOKE CLOUD

- SPACE geOMETRY

- SPACE VENTILATION
CRITICAL EVENTS

- IGNITION OF SECOND ITEM

- IGNITION OF NEW ITEMS (OR SURFACES)

- FLASHOVER

- fire decay - POST FLASHOVER

- NO FLASHOVER

- ignition external to SPACE OF ORIGIN

Fic. 10. Intraroom (intraspacial) development phase.

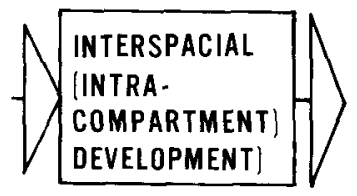

REALMS

- deCElerating PROPAgation

- accelerating propagation

- STEADY-STATE

WITHOUT FLASHOVER POST FLASHOVER
DOMINANT FACTORS

- INCIDENT ENERGY

POSITION

LEVEL

FORM

- fLAME EXTENSION

- cOMBUStiBle EFFLUENT

- EXPOSED FUEL

- SPACE GEOMETRY

- VENTILATION
CRITICAL EVENTS

- IGNITION EXTERNAL TO SPACE OF ORIGIN

- eSTABLISHMENT OF DECELERATING TREND

- ESTABLISHMENT OF ACCELERATING TREND

- entry OF NEW FUEL

- fLASHOVER

FrG. 11. Interspacial (intracompartment) development phase. 


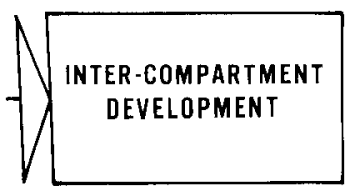

REALMS

- DeVelopMent fRom

DISCRETE IGNITIONS

- SUPPORTED DEVELOPMENT

(EXPOSURE FROM

RADIATING SURFACES)

- massive enERgy tRanSfer

IMAJOR STRUCTURAL

FAILURE OF BARRIER)
DOMINANT FACTORS

- eXPoSing SEVERITY

- TOTAL ENERGY

- ENERGY LEVEL

- DURATION OF EXPOSURE

- HEAD PRESSURE OF

EXPOSING FIRE

- incident energy on member

- BARRIER

- CLOSURE (DOOR, ETC. )

-BEARING ELEMENT

- gRavitr loAdINg

- element CAPABILITIES

- STRUCTURAL

- THERMAL

- COMPLETENESS
CRITICAL EVENTS

- fLASHOVER IN EXPOSING SPACE

- DISCRETE IGNITION

- MASSIVE IGNITION

- geOMETRY CHANGE

Fia. 12. Intercompartment development phase.

Realms, Dominant Factors, and Critical Events. Figures 8 through 12 have been developed covering the five phases shown in Fig. 6. In each of these phases, the figure shows likely realms, expected dominant factors, and critical events expected within that phase. In no case is it expected that all realnis depicted will occur. In each case the first critical event is the most likely entry into the realm and the last critical event is the definition of an event that would result in passing from the final realm in the phase into the first realm of the next phase.

Human Behavior Sequence. The basic criterion for the protection of humans during fire is the avoidance of occupancy of the same space at the same time by people and conditions intolerable to people. In fire situations the fire effects may be moving, or of consequence in only a very limited area. The humans involved may or may not be mobile and their safety may or may not be dependent on their actions.

Studies of the types of actions (episodes) involved in human behavior in fire are rela- tively few and rudimentary in nature. To date, however, they would indicate that the types of actions can be classified as: investigate, flight, attack, alarm, rescue, and no action. These are not in sequence and the probability of any action is unknown. At this time the state-of-the-art is simply one of recognizing the types of episodes and searching for any indication of which factors are dominant.

State's Conditions-Human Behavior Sequence. Looking ahead towards the time when more rational predictions of human actions can be made, the only state's condition necessary to describe person or persons involved is:

Position-Expressed in terms of a vector that defines not only the location of the person(s) but the rate and direction of movement.

With this it is possible to visualize the expression of the rate constant in terms of the formula: 


$$
\dot{q}_{n}=\dot{q}_{j} \mathrm{e}^{k t}
$$

FIRE BEHAVIOR

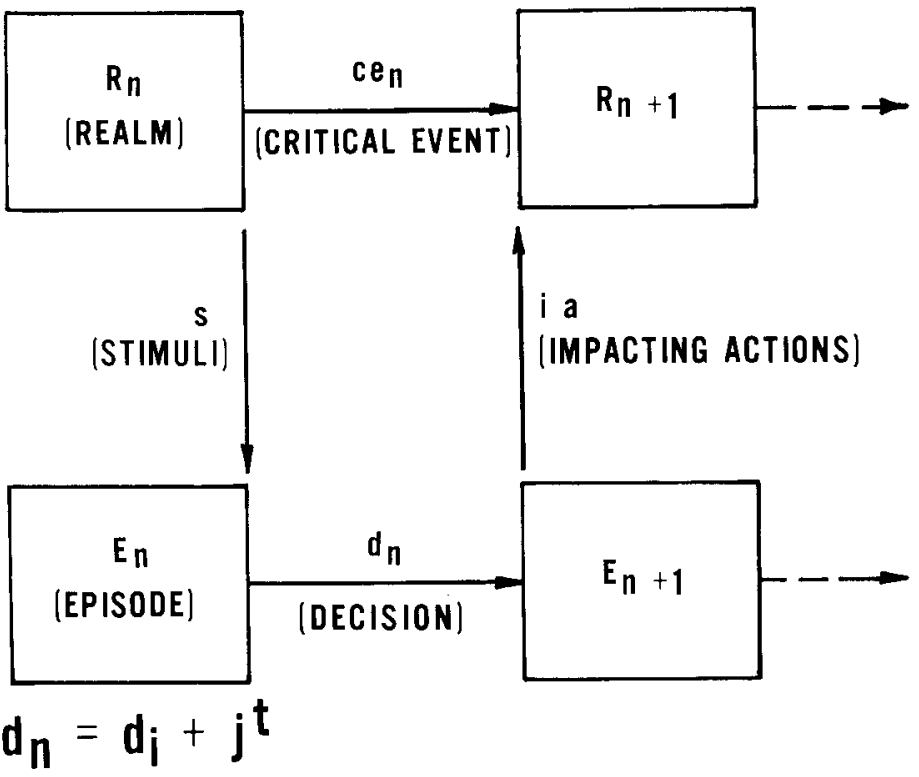

FIG. 13. General model.

$$
\begin{aligned}
d_{n}= & d_{i}+j t \\
d_{n}= & \text { position at any instant within an } \\
& \text { episode } \\
d_{i}= & \text { position at another prior instant } \\
& \text { within the same episode } \\
t= & \text { time between } i \text { and } n \\
i= & \text { rate constant for the episode. }
\end{aligned}
$$

This can be seen as a linear formula versus the exponential formula used for energy development. In addition, the nonphysical factor of human decision is visualized as an efficiency factor. Physically no human can react faster than his personal maximum speeds and cannot occupy less space than that required by his body. In practice, however, these capabilities can be reduced by the types of decisions made.

General Model. Figure 13 is a general model of the human behavior and fire behavior sequences. As indicated by this model, fire behavior is looked upon as a series of independent realms connected by critical events while human behavior is a series of independent episodes connected by decisions. The two sequences influence each other with stimuli that flow from the fire behavior sequence to the human behavior sequence causing action or impacting on the well-being of the humans. The flow of stimuli is caused by the fire behavior sequence and is proportional to it but entirely separate from it. Flow from the human behavior sequence to the fire sequence is in the form of impacting actions. The type of impacting action can be one countering the development of fire such as fire attack activities or the closing of doors or other activities aimed at confining the fire or relieving its effects. Impacting actions can also be detrimental to the restraint of fire due to activities such as evacuees leaving doors open or ineffective attempts at fire control activities that result in further spread and development. Human behavior can also progress through part or all of its sequence without impact- 


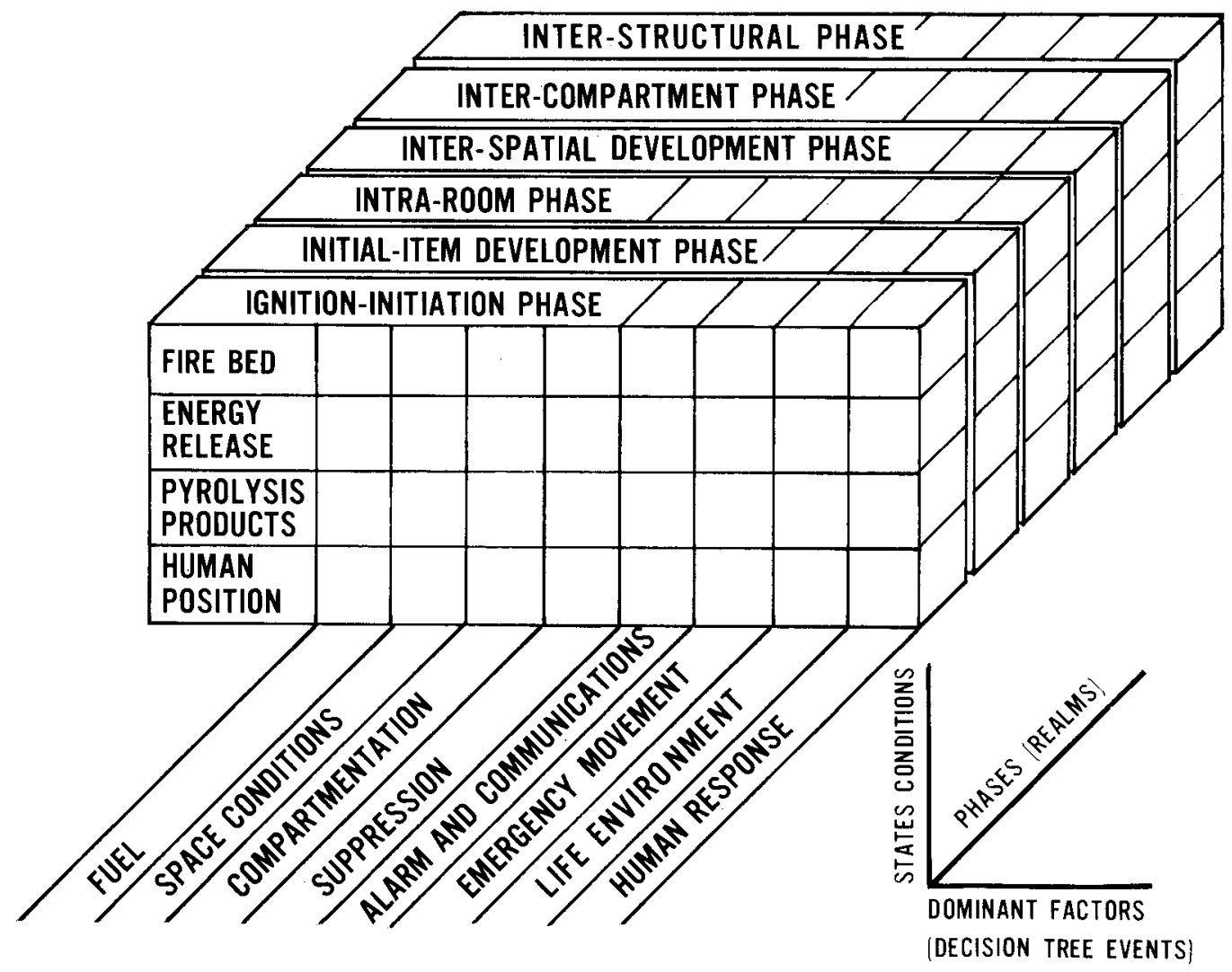

FIG. 14. Matrix.

ing in any way on the fire, such as where evacuation takes place without any action that causes the fire to grow or be confined.

Figure 14 is a three-dimensional matrix interfacing State's Conditions, Phases (Realms), and Dominant Factors (Decision Tree Events). The purpose of the matrix is to direct and organize the knowledge base in fire science and technology in a manner focused on specific realms, conditions, or determinants. As the matrix inputs are developed, the knowledge derivable from fire science and technology can be fed into a decision analysis system for determining building fire safety requirements, giving a significantly increased level of confidence in the product.

A proposed program for this transition is: A. The assembly and organization of the existing knowledge base to identify the relationship of the knowledge to each of the intersections in the matrix, and to identify apparent knowledge voids.

B. The identification of the significant phenomenon controlling the $k$ factor or comparable constant in each matrix block (realm) and the phenomenon that can cause critical events resulting in a transition to another realm.

C. Development of models for predicting the fire phenomena and for the response of the facility, its contents, and its occupants.

D. Improvement of these models towards a complete system of deterministic models covering all realms, and critical events to complete all connections and 
interfaces possible through expansion of the general model, Fig. 14.

L. For each realm, episode, and critical event, identification of the impact (sensitivity) of each event or group of events (branch) of the decision tree.

F. Conducting parametric analyses of the models to develop possible scenarios and their resulting impact. Relating the probability of each scenario to accident loss data. Entering these values into the building fire safety design system.

Relevance to Decision Tree. In an analysis of the fire behavior sequence, the $k$ factor provides a mechanism for the understanding of fire development which provides an input to the tree. The specific impact on cach individual decision tree event will be consistent through the course of a realm. Some events on the tree will have major impact on the course of fire in that realm, others lesser or no influence. For example, the specific fuel ignition characteristics in combination with the ignition source dominate the course of fire on the initial surface ignited and establish the roalm. The fire resistance of the structure plays no part in this realm. Conversely in a fully involved room fire, the structural fire resistance along with the ventilation and total fuel mass are the principal control factors. In this realm the ignitability or flame spread characteristics are of insignificant impact. The decision tree, therefore, is a mechanism for describing all events that can influence achicvement of the top event (Fire Safety Objectives) during all possible realms of the fire. In an individual realm it is normal for some of the events to have no significance.

This potential relationship between the $k$ factor and the decision tree provides new mechanisms for understanding and application of systems analysis. Since the $k$ factor accounts for fire growth in terms of time, it will be possible to interlock the life-safety aspect of the protection branch of the decision tree to the control branch.

\section{REFERENCES}

General Services Administration. 1971. International Conference on Fire Safety in High Rise Buildings. Washington, DC.

. 1972. Interim guide to goal-oriented systems approach to building fire safety. Appendix D. Building Fire Safety Criteria (PBS P5920.9). Washington, DC. - 1974. Fire safety systems-Richard B. Russell Courthouse and Federal Office Building, Atlanta, GA. Washington, DC.

Nelson, H. E. 1972. Systems analysis of the energy environment in buildings. Fire Tech. $8(1): 53-66$.

RocketT, JoHs A. 1969. Objectives and pitfalls in the simulation of building fire with a computer. Fire Tech. 5:311-321.

Society For Industrial and Applied MatheMatics. 1975. Reliability and fault tree analysis. Philadelphia, PA.

\section{BIBLIOGRAPHY}

Publications on The Systems Approach to Fire Safety Analysis

Apostolakis, GeORGE. 1974. Mathematical methods of probabilistic safety analysis. Univ. Cal., Los Angeles.

Barlow, Richard E., and Purnendu Chatterjee. 1973. Introduction to fault tree analysis. Operations Research Center, College of Engineering, Univ. Cal., Berkeley. Pp. 11-16.

Chatter jee, P. 1974. Fault tree analysis: Reliability theory and systems safety analysis. Univ. Cal., Berkeley.

Fenguson, J. B. n.d. The derivation of a systems approach to fire safety performance requirements. National Bureau of Standards, Washington, DC.

General Services Administration. 1971. Preliminary task group reports on fire safety systems for high-rise buildings. Washington, DC.

1971. International Conference on Fire Safety in High-Rise Buildings, April 12-16Airlie House-Warrenton, VA. Washington, DC.

. 1971. Procecdings: Reconvened International Conference on Fire Safety in HighRise Buildings. Washington, DC.

. 1972. Building fire safety criteria. Washington, DC.

. 1973. Conference on Fire Safety for Buildings Research Practice Needs. Washington, DC.

- 1975. Fire safety systems-Richard B. Russell Courthouse and Federal Office Building, Atlanta, Georgia. Washington, DC.

GSA, HUD, NBS, NSF. Research Practice Needs, Conference on Fire Safety for Buildings: 
Airlie Ilouse. Airlie, Virginia, July 18-20, 1973.

Hakmathy, T. Z. 1974. Design approach to fire safety in buildings. Prog. Arch. 4:82-87.

- 1974. Designers option: Fire resistance or ventilation. Nat. Res. Coun. Tech. Pap. 436:277-282. Ottawa, ON.

INGBERG, S. H. 1930. The severity of building fires. Nat. Bur. Stand., Washington, DC. (AHC).

National Fire Protection Association. 1975. Designing buildings for fire safety. Boston, MA.

1976. Systems approach to fire protection. Doc. SPP-36. Boston, MA.

Nelson, H. E. 1974. The application of systems analysis to building fire safety design. Gen. Serv. Admin. Washington, DC.

-. 1972. Systems analysis of the energy enviromment in buildings. Fire Tech. 8(1): 53-66.

Rockl:тt, J. A. 1969. Objectives and pitfalls in the simulation of building fire with a computer. Fire Tech. 5:311-321.

Seigel, L. G. 1972. Performance approach to the design of fire-resistive buildings. NBS Spec. Publ., Vol. 1, No. 361, Nat. Bur. Stand. Washington, DC. Pp. 557-566.

SOCIETy For INDUSTRIAL aNd Applied MatheMATICS. 1975. Reliability and fault tree analysis. Philadelphia, PA.

Stevens, R. E. 1972. For architects and builders-Decision trees and standards. Fire J. 66(4):54-55.

The Combustion Institute. 1974. Fifteenth International Symposium on Combustion. Pittsburgh, PA.

Thompson, R. I. 1975. The decision tree for fire safety systems analysis. Fire J. $69(4)$ : $61-67 ; 69(5): 27-34 ; 69(6): 35-39,89$.

. 1974. For architects and builders. Fire J. $69(3): 26-27$.

Wu, C., and J. Gerenita. 1973. Analog simulation of a safety probability model for high-rise buildings. Fire Tech. 9:176-181. 